\title{
Removal of inhibitor(s) of the polymerase chain reaction from formalin fixed, paraffin wax embedded tissues
}

\author{
S F An, K A Fleming
}

\begin{abstract}
A problem associated with use of the polymerase chain reaction to amplify specific DNA fragments from formalin fixed, paraffin wax embedded tissues is the not infrequent failure of amplification. One possible reason for this could be the presence of inhibitor(s), which interfere with the activity of the reaction. It has been shown that such inhibitor(s) exist when amplifying the human $\beta$ globin gene (which exists in human genomic DNA as a single copy gene) from routine clinical samples. A variety of methods to remove such inhibitor(s) were investigated. The results indicate that inhibitor(s) are removed by proteinase $K$ digestion, followed by purification with phenol/ chloroform, and centrifugation through a Centricon-30 membrane (30 000 molecular weight cut off). Other factors, including the length and concentration of the DNA sequence to be amplified, can also affect amplification.
\end{abstract}

The polymerase chain reaction ( $P C R$ ) permits specific and rapid amplification of nucleic acid sequences from a variety of materials, including blood, hair and fresh or frozen tissues. ${ }^{1}$ In view of the large amount of archival material stored in pathology departments, retrospective analysis of formalin fixed, paraffin wax embedded tissues has also been performed. ${ }^{2-6}$ Several reports, however, have indicated that the PCR on such material is not reliable, the failure rate varying between $2-31 \% .{ }^{4-8}$ We have also noted this intermittent failure of amplification from such tissues. ${ }^{9}$

The purpose of this study was, therefore, to investigate the causes of non-amplification by the PCR when using formalin fixed paraffin wax embedded tissues and to devise a reliable reproducible method of amplification of nucleic acid from such tissues.

Nuffield Department of Pathology and Bacteriology, University of Oxford, John Radclifie Hospital, Oxford OX3 9DU

$S$ F An

K A Fleming

Correspondence to:

Dr K A Fleming

Accepted for publication 22 May 1991

\section{Methods}

Blocks of formalin fixed paraffin wax embedded tissue were chosen at random from the files of Nuffield Department of Pathology and Bacteriology, University of Oxford, John Radcliffe Hospital, Oxford. The material had been processed between 1988-1990. A variety of tissue types were amplified (table). Fixation was in neutral formol/saline. The time of fixation varied between 24 and 48 hours. Processing was by standard methods-that is, dehydration in graded alcohols, clearing in xylene, and embedding in Paraplast paraffin using a VIPII (Tissue Tek) processor.

Paraffin wax sections $(10 \mu \mathrm{M})$ were cut and placed in a $1.5 \mathrm{ml}$ Eppendorf tube. The number of sections varied according to the surface area of the tissue block. About $7 \mathrm{~mm}^{3}$ was taken for digestion. The paraffin was removed by washing with Citroclear (HD Supplies, England) for five minutes and $95 \%$ ethanol for five minutes, following by drying at $95^{\circ} \mathrm{C}$ for 90 minutes.

Five methods were tried for DNA extraction:

(1) No additional procedure after dewaxing, the PCR reaction mix being added to the tissue.

(2) After dewaxing, the tissue was boiled for 20 minutes in $200 \mu \mathrm{l}$ of distilled water and a variable amount of the supernatant used for amplification. Sometimes this supernatant was passed through a Sephadex G50 column before attempting amplification.

(3) Treated as method 2, but additionally digested with proteinase $\mathrm{K}$ (Boehringer Mannheim, East Sussex, England) final concentration $1 \mathrm{mg} / \mathrm{ml}$ in $100 \mathrm{mM}$ phosphate buffered saline (pH 7-2). Digestion was performed at $37^{\circ} \mathrm{C}$ overnight. The supernatant was boiled to inactivate the proteinase $K$ and then used for amplification.

(4) Treated as method 3, but the supernatant was additionally extracted once with an equal volume of phenol (equilibrated with $100 \mathrm{mM}$ TRIS (pH 8.0) $0.1 \%$ hydroxyquinoline), once with 1:1 mixture of phenol and chloroform (a 24:1 (v/v) mixture of chloroform and iso-amyl

\section{List of formalin fixed paraffin wax embedded tissues}

\begin{tabular}{lc}
\hline Tissues & No of samples \\
\hline Liver & 3 \\
Skin & 7 \\
Rectum & 1 \\
Ovary & 2 \\
Bladder & 1 \\
Omentum & 1 \\
Cervix & 1 \\
Uterus & 1 \\
Rectal Polyp & 2 \\
Appendix & 1 \\
Stomach & 1 \\
Thyroid & 1 \\
Heart & 1 \\
Prostate & 1 \\
Gum & 1 \\
Lymph node & 1 \\
Kidney & 1 \\
Total & 1 \\
\hline
\end{tabular}


alcohol), and once with chloroform (as above). The resultant supernatant was used for amplification.

(5) Treated as method 4, but the supernatant was centrifuged through Centricon-30 or Centricon-10 membrane (Amicon UK) by using a Beckman JA-14 Rotor (angle $25^{\circ}$ ) at $5000 \times \mathrm{g}$ for 30 minutes. Initial volume is $2 \mathrm{ml}$, the final volume is about $60 \mu \mathrm{l}$. The retentate was washed twice with $1 \mathrm{ml}$ of distilled water. The final retentate was used for amplification.

EFFECT OF PROCESSING ON THE PCR

To examine the effect of processing on the PCR fresh tissues were processed in several ways (processed by Dr AL Morey, Nuffied Department of Pathology and Bacteriology, University of Oxford): (a) frozen immediately; (b) fixed with formalin, rehydrated in Dextran, then frozen; (c) fixed with formalin, dehydrated in ethanol, rehydrated in water and Dextran, then frozen; (d) fixed with formalin, dehydrated in ethanol, cleared in xylene and ethanol, rehydrated in Dextran, then frozen.

Frozen sections were boiled for 20 minutes in $200 \mu \mathrm{l}$ distilled water and the supernatant used in the PCR.

\section{$\beta$ GLOBIN PRIMERS AND PLASMID}

Amplification was performed for the whole of the first exon and intron and part of the second exon of the human $\beta$ globin gene. All primers were designed from sequence data. ${ }^{10}$ Their sequences are written from $5^{\prime}$ to $3^{\prime}$ :

Primer 1: ATGGTGCACCTGACTCCTGAGG

Primer 2: GCCATCACTAAAGGCACCGAGC

A 355 base pair fragment is flanked by primer 1 and primer 2 .

Primer 3: CTGTGGGGCAAGGTGAACG

Primer 4: CAAAGGACTCAAAGAACCTC

Primer 3 and primer 4 flank a 227 base pair fragment which is nested within the 355 base pair fragment.

$\beta$ globin plasmid is a recombinant plasmid containing the whole genome of human $\beta$ globin (4.4 kilobase pairs) in PstI site of PBR322 (donated by Dr J Old, Nuffield Department of Medicine, Univeristy of Oxford).

PCR

For demonstration of presence and absence of inhibition a single round PCR alone (primers 3 and 4) was used with or without exogenous $\beta$ globin plasmid. For amplification of endogenous $\beta$ globin gene from formalin fixed paraffin wax tissues two stage nested PCR was performed. The first round was with primers 1 and 2 ; the second was with primers 3 and 4. The reaction mixture of $100 \mu$ l contained 100 pmol each of primers; $0.2 \mathrm{mM}$ each of dATP, dCTP, dGTP and dTTP; and 2.5 U Amplitaq DNA polymerase in PCR buffer (10 mM TRIS-HCl, pH 8.3, $50 \mathrm{mM} \mathrm{KCl}$, $1.5 \mathrm{mM} \mathrm{MgCl}, 0.001 \%$ gelatin). For the first round, $50-300 \mathrm{ng}$ of extracted human gen- omic DNA was used as a template. Fifty cycles of PCR were performed, consisting of thermal denaturation at $94^{\circ} \mathrm{C}$ for two minutes, primer annealing at $55^{\circ} \mathrm{C}$ for two minutes, and extension at $72^{\circ} \mathrm{C}$ for three minutes. For the second round of amplification (with primers 3 and 4), a 1 in 20 dilution of first round product was used as a template for 25-30 cycles of amplification.

\section{Results}

DEMONSTRATION OF INHIBITOR OF PCR IN TISSUES To show the presence of an inhibitor of the PCR in tissues a single round (primers 3 and 4) PCR was performed with tissue section extracts (prepared by method 2) with or without added exogenous $\beta$ globin plasmid $(300 \mathrm{pg})$. Figure 1 shows that adding increasing amount of tissue extracts to the reaction mix resulted in inhibition of amplification of the exogenous $\beta$ globin plasmid. This applied not only to frozen tissue, but also to processed tissue sections. This experiment also shows that endogenous $\beta$ globin gene can be amplified by a single round PCR from frozen tissue (fig IA lanes 1,3,5), but cannot be similarly amplified from material which has been formalin fixed and processed (fig 1B lanes 1,3,5).

REMOVAL OF INHIBITOR FROM TISSUES

A variety of methods were investigated for removal of the tissue inhibitor. Figure 2 shows that the inhibitor cannot be removed by boiling and proteinase $\mathrm{K}$ digestion. It is necessary to extract with phenol and centrifuge through a Centricon-30 filter. Both of these latter procedures are necessary, as no amplification was obtained without Centricon-30 filtration (lanes 1-8).

EFFECT OF TARGET DNA QUANTITY AND QUALITY The effect of varying the amount of target DNA extracted from formalin fixed, paraffin wax embedded tissues is shown in figs 3 and 4 . These experiments used a two stage nested PCR. Figure 3B shows that some samples extracted from such tissues still failed to amplify, despite use of the full extraction

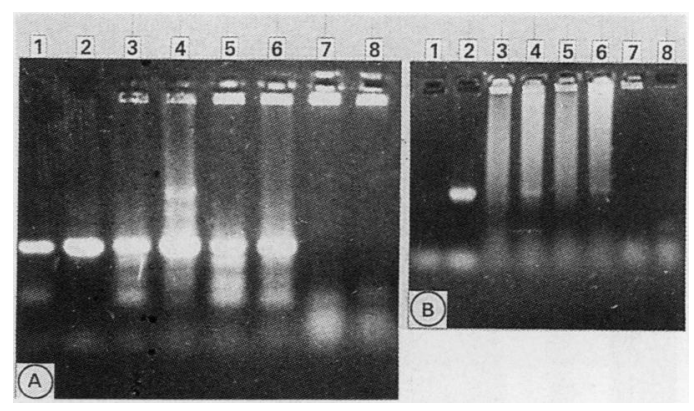

Figure 1 Demonstration of inhibition of the PCR in frozen and formalin fixed paraffin wax embedded tissues. Increasing amounts of tissue extract (method 2) were added to the PCR mix; Lanes 1,2:1 $\mu l$; Lanes 3,4:5 $\mu l$; Lanes 5,6:15 $\mu l$; Lanes 7,8:30 $\mu l$ odd number lanes: no added exogenous $\beta$ globin plasmid DNA; Even number lanes: added exogenous $\beta$ globin plasmid DNA. Figure $1 A$ Frozen tissue. Figure $1 B$ Formalin fixed paraffin wax embedded tissue. 
Figure 2 Removal of extracted by method (1); lanes 3,4:DNA extracted by method (2); lanes 5,6: extracted by method (4), lanes 9,10:DNA extracted by method (5), as in fig 1 , even lanes had added exogenous $\beta$ globin plasmid. inhibitor from tissues. Lanes 1,2: DNA DNA extracted by method (3); lanes 7,8:DNA

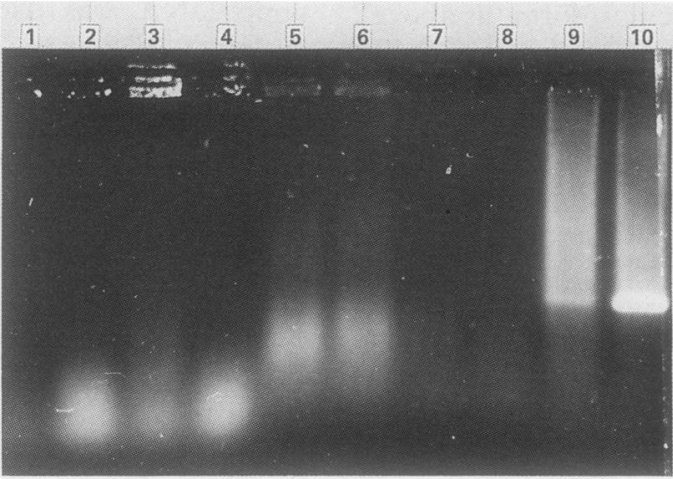

procure. Comparision with the ethidium gel electrophoresis (fig 3A), however, shows that the failure to amplify was associated with absence of detectable extracted DNA. This effect was confirmed by deliberately varying the amount of DNA extracted from two tissue blocks (fig 4). This clearly shows that less than $50 \mathrm{ng}$ of target DNA can be associated with failure to amplify and that up to $2 \mu \mathrm{g}$ can be amplified successfully.

Another factor investigated was the size of the target DNA fragment. While amplification from formalin fixed, paraffin wax embedded tissues could occasionally be obtained with the $\beta$ globin external primers alone (a single round of PCR), not infrequently this single round of amplification failed to give detectable product (data not shown). Accordingly, a second round of amplification, using internal primers was performed. This resulted reliably in a 227 base pair product. In contrast, single round amplification of formalin fixed, paraffin wax embedded tissues of a smaller fragment (110 base pairs) was usually successful (data not shown), suggesting that the failure of single round amplification of the 355 base pair fragment was due the size of the target sequence.

USE OF OPTIMISED PROTOCOI

To determine the reliability of the optimised DNA extraction procedure 27 formalin fixed, paraffin wax blocks were used for amplification of endogenous human $\beta$ globin gene. All were amplified successfully.
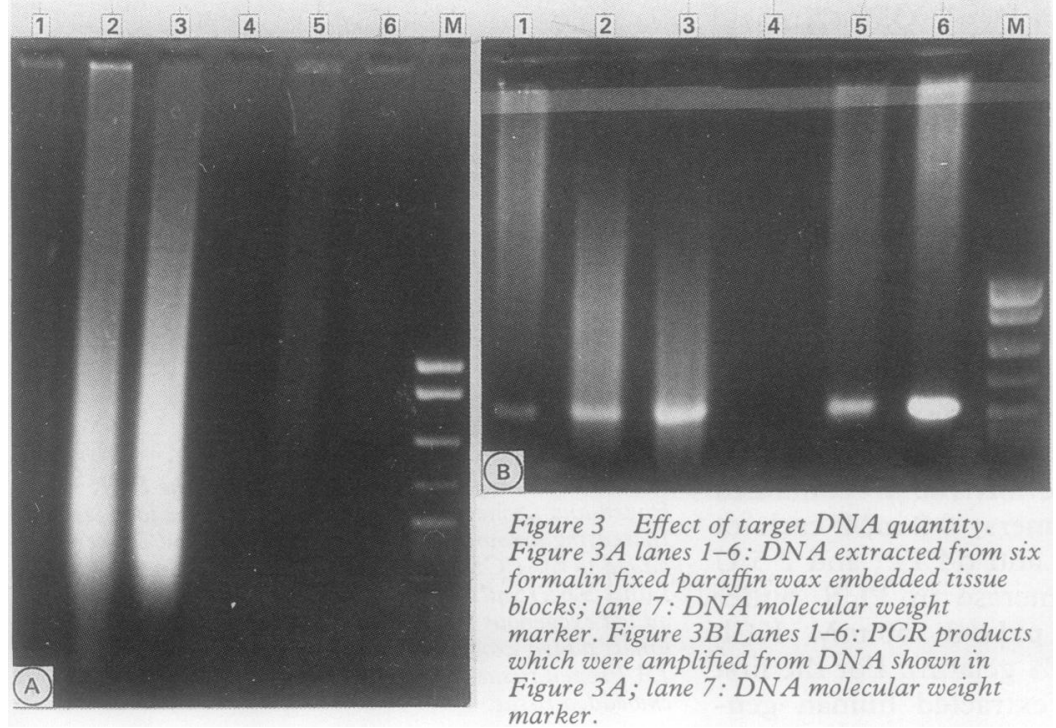

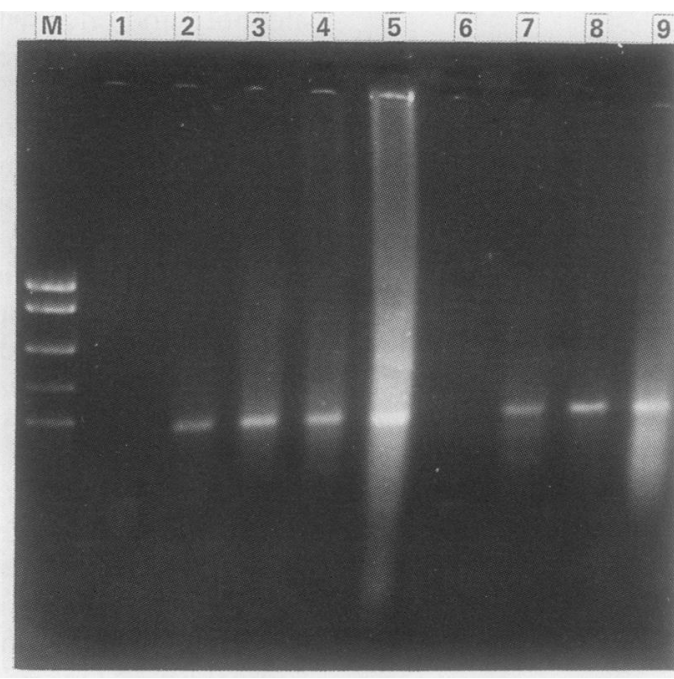

Figure 4 Effect of varying the amount of target DNA. Lanes 1-5: block $(A)$; lane 1:20 ng of DNA; lane 2:50 ng of DNA; lane 3: $100 \mathrm{ng}$ of DNA; lane 4:1 $\mathrm{g}$ of DNA; lane 5:2 $\mu$ g of DNA; lanes 6-9: block $(B)$; lane 6: $20 \mathrm{ng}$ of DNA; lane 7:50 ng of DNA; lane 8: $100 \mathrm{ng}$ of DNA; lane 9:2 $\mathrm{\mu g}$ of DNA; lane M:DNA molecular weight marker.

\section{Discussion}

The above results confirm intermittent failure of the PCR in formalin fixed, paraffin wax embedded tissue, as previously reported, ${ }^{4-9}$ although this effect is not universal and successful amplification from such material can be obtained in about $80 \%$ of samples simply by dewaxing the tissue section (unpublished observations). If it is essential to amplify every available sample-for instance, if there is only a small amount of tissue or few samples-then failure to amplify all samples becomes a major problem.

The results of our investigation show that inhibition is present in both frozen and formalin fixed paraffin wax embedded tissue and increases with increasing amounts of tissue or tissue extract. These effects are of some relevance as a frequent response to failure of amplification of a particular sample is to increase the amount of starting material. From our results, this paradoxically will have the effect of producing even more inhibition of the PCR. Indeed, successful amplification may be obtained on occasions by reducing the amount of target material-for example, taking only a $1 \mathrm{~mm}^{2}$ fragment of the tissue section (unpublished observations). This is dependent on the cellularity of the tissue, however, and the distribution of the target you are seeking to amplify. For example, a tissue with relatively sparse cellularity in relation to volume (muscle) may not have enough DNA present in a small fragment. Furthermore, there may be heterogeneous distribution of target in the tissue (virus), and sampling a small fragment may miss the target.

Accordingly, we assessed a variety of methods of removing this inhibition. Initially, samples were boiled for 20 minutes, then the supernatant was amplified with or without prior filtration through a Sephadex G50 column. This has been reported to remove inhibition of the PCR. ${ }^{4-11}$ This did not permit consistent 
amplification in our hands. Simple protease digestion of the tissue alone was also incapable of totally removing inhibition, even if extended up to five days. Indeed, we found that the efficiency of the PCR did not improve, or even decreased, when using samples protease digested longer than 24 hours (data not shown). Several proteolytic enzymes were used, including pepsin $/ \mathrm{HCl}$, proteinase $\mathrm{K}$ and protease 8 (Subtilopeptidase A, Sigma). Of these, in the optimised protocol, proteinase $\mathrm{K}$ seemed to be the most efficient (data not shown).

As simple proteolytic digestion had not removed inhibition we proceeded to extract the digestion product with phenol. Use of this phenol extracted material resulted in more frequent amplification. Unfortunately, however, this was still not totally reliable and further treatment was necessary. This was performed by purifying and concentrating the DNA in a Centricon 10 or 30 filter. This full procedure resulted in reliable reproducible amplification of exogenously added $\beta$ globin plasmid and thus apparent removal of inhibition.

The nature of the inhibition has not been systematically investigated, but from our results it seems to be resistant to boiling, is not destroyed by some proteinases, is not soluble in some organic solvents and has a molecular weight of less than 10 kilodaltons. It is also not tissue or species specific. ${ }^{9}$ As it is present in frozen tissues this indicates that it is endogenous and is not induced by formalin fixation or other steps in tissue processing.

Despite implementation of this protocol we subsequently noted that some samples of DNA extracted from formalin fixed, paraffin wax embedded tissues failed to show amplification of endogenous $\beta$ globin (fig 3). Investigation of the amount of the extracted target nucleic acid showed that this failure to amplify seemed to be associated with the total absence of detectable DNA on agarose gel electrophoresis. The importance of adequate amounts of extracted DNA for amplification are shown in fig 4, where use of less than $50 \mathrm{ng}$ of target genomic DNA resulted in failure to amplify. Thus as tissue blocks are of different surface areas and as tissues are of varying cellularity and DNA content, equal volumes of tissue sections should be used for DNA extraction (by varying section numbers) and DNA quantitated and equalised before amplification.

Additionally, the size of the extracted DNA proved to be a controlling factor in amplification. This is shown by the failure to amplify reproducibly large lengths of target DNA (greater than 300 base pairs) by single round PCR, in comparision to small fragments (110 base pairs). One likely explanation of this is degradation of the target DNA (see below). In view of this, amplification of relatively small lengths of DNA, particularly by nested PCR, was used and proved reliable and reproducible. Thus by combining the optimised extraction procedure (method 5) with nested PCR for relatively small fragments and using at least $100 \mathrm{ng}$ of target genomic DNA, a 227 base pair fragment of endogenous $\beta$ globin could be amplified from 27 out of 27 randomly chosen, routine surgical, formalin fixed, paraffin wax samples, representing 17 different tissue types.

The DNA degradation noted above probably results from several factors, including fixation. Several groups $s^{5-7} 12-14$ have reported the effects of fixation on the efficiency of the PCR and on DNA degradation. Different types of fixation can give very different PCR amplification rates, with buffered formalin being better than unbuffered formalin. ${ }^{7}$ Furthermore, as nucleases may also have an important role in DNA degredation in tissue the extracted DNA was heated at $95^{\circ} \mathrm{C}$ for 90 minutes for drying and inactivation of nuclease.

We have occasionally found that some samples fail to amplify even using the optimised protocol. On repeating the procedure on further tissue sections, however, successful amplification was obtained. It is not clear whether this represents random technical error or a "tube" failure of the PCR.

In conclusion, the above results indicate the absolute need for inclusion of an endogenous positive control when performing PCR amplification, especially on formalin fixed, paraffin embedded wax tissues. This is in addition to the requirement for a negative control, to correct for contamination. ${ }^{15}$ If some samples fail to amplify then use of adequate amounts of target DNA, purified by the optimised extraction procedure and targeting of a sequence length of less than 300 base pairs, should permit successful amplification.

This work was supported by the Foundation for the Study of Infant Deaths. We are grateful to Dr Dennis Lo, Dr Eric PH Yap, and British Biotechnology Ltd for supplying the human $\beta$ globin primers, and Dr F Pezzella for expert assistance.

1 Innis MA, Gelfand D, Sninsky JJ, White TJ. PCR protocols Principles and applications. Academic Press, New York 1990.

2 Impraim CC, Saiki RK, Erlich HA, Teplitz RL. Analysis of DNA extracted from formalin-fixed, paraffin-embedded tissue by enzymatic amplification and hydridization with tissue by enzycicicion with Commun 1987;142:710-6.

3 Lai-Goldman M, Lai E, Grody WW. Detection of human immunodeficiency virus (HIV) infection in formalin-fixed, paraffin-embedded tissue by DNA amplification. Nucleic paraffin-embedded tissue
Acids Res 1988;16:8191.

4 Lampertico P, Malter JS, Colombo M, Gerber MA. Detection of hepatitis B virus DNA in formalin-fixed, paraffinembedded liver tissue by the polymerase chain reaction. Am J Pathol 1990;137:253-8.

5 Rogers BB, Alpert LC, Hine EAS, Buffone GJ. Analysis of DNA in fresh and fixed tissue by the polymerase chain reaction. Am J Pathol 1990;136:541-8.

6 Jackson DP, Lewis FA, Taylor GR, et al. Tissue extraction of DNA and RNA and analysis by the polymerase chain reaction. J Clin Pathol 1990;43:499-504.

7 Shibata D, Hu E, Weiss LM, et al. Detection of specific t 14 ; 18) chromosomal translocations in fixed tissues. Hum Pathol 1990;21:199-203.

8 Coates PJ, d'Ardenne AJ, Khan G, Kangro HO, et al. Simplified procedures for applying the polymerase chain reaction to routinely fixed paraffin was sections. J Clin reaction to routinely

9 Lo Y-MD, Mehal WZ, Fleming KA. In vitro amplification of hepatitis B virus sequences from liver tumour DNA and from paraffin wax embedded tissues using the polymerase chain reaction. J Clin Pathol 1989;42:840-6.

10 Lawn RM, Efstratiadis A, O'Connell C, Maniatis T. The nucleotide sequence of the human $\beta$-globin gene. Cell 1980;21:647-51.

11 De Franchis R, Cross NCP, Foulkes NS, Cos TM. A potent inhibitor of Taq polymerase copurifies with human genomic DNA. Nucleic Acids Res 1988;16:10355.

12 Wu AM, Ben-Ezra J, Winberg C, et al. Analysis of antigen receptor gene rearrangements in ethanol and formaldehyde-fixed, paraffin-embedded specimens. Lab Invest 1990;63:107-14.

13 Bramwell NH, Burns BF. The effects of fixative type and fixation time on the quantity and quality of extractable DNA for hydridization studies on lymphoid tissue. Exp Hematol 1989;16:730.

14 Tokuda Y, Nakamura T, Satonaka K, et al. Fundamental study on the mechanism of DNA degradation in tissues

15 Lo Y-MD, Mehal WZ, Fleming KA. False positive results and the polymerase chain reaction. Lancet 1988;ii:679. 